\title{
Parents' Perspectives on Curbing Gun Violence Among Children in Three Counties in Indiana
}

\author{
Cecilia S. Obeng and Sean M. Bowman \\ Indiana University
}

\begin{abstract}
The occurrence of fatalities associated with gun violence among children, as reported in the media, makes studying gun violence and its prevention among children a priority. The purpose of this study was to investigate parents' views on gun violence and whether gun safety education should be provided in schools. Thematic analysis was conducted on open-ended questions and descriptive statistics for closedended questions. Of the 200 participants, 79\% $(n=158)$ of them indicated that gun safety instructions should be taught in schools, whereas $21 \%(n=42)$ disapproved. Forty-five percent of the 158 participants who agreed to gun safety education suggested that police/military personnel teach gun safety to children. Overall, the parents questioned believed that gun safety education would help children to understand the seriousness of this issue. Some parents were not in favor of gun safety education. However, because the overwhelming majority was in favor of it, it is important for stakeholders in schools to consider offering it as one possible way to reduce gun violence among children.
\end{abstract}

(C) 2013 Californian Journal of Health Promotion. All rights reserved.

Keywords: children, gun violence, schools, parents

\section{Introduction}

\section{Guns at Home}

Approximately one third of children live in homes where their parents or guardians keep guns (Cook \& Ludwig, 1996; Schuster, Franke, Bastian, Sor, \& Halfon, 2000; Johnson, CoyneBeasley, \& Runyan, 2004; Children's Defense Fund, 2010). The presence of guns in the home creates an environment in which children have access to guns, a situation that contributes to the unfortunate but regular occurrence of fatalities associated with morbidity and mortality among children (Children's Defense Fund, 2010; Cook \& Ludwig, 1996; Schuster, Franke, Bastian, Sor, \& Halfon, 2000; Johnson, Coyne-Beasley, \& Runyan, 2004; Becker, Olson, \& Vick, 1993).

The amount of gun violence among children is high. In 2011, the Centers for Disease Control and Prevention (CDC) reported that an estimated $16.6 \%$ of youth, ages 9 to 12 carried at least one weapon within the previous 30 days prior to a survey, and $5.1 \%$ of youth carried a handgun. It was also estimated that $7.4 \%$ of youth were threatened or injured with a weapon on school property one or more times in the preceding year (CDC, 2012). Furthermore, it was estimated that $7.1 \%$ of youth had had at least one incident where they had attacked another person with the intention to hurt or seriously cause harm (NSDUH, 2010).

\section{Curbing Gun Violence in Children's Environment}

The views to curb gun violence among children are diverse. For example, Almond (2008) posed a question as to whether imposing gun control laws have the potential to reduce school violence. Cummings et al. (1997) highlighted the successes of legislation that makes gun owners responsible for gun storage, indicating that such legislation decreases unintentional shooting deaths as well as gun-related homicide and suicide. The authors concluded that such precautionary legislation has a positive effect in lowering gun-related injury and death among children.

Becker et al. (1993) discusses unintentional firearm deaths among children in New Mexico, 
which is second only to Alaska in terms of gun-

related deaths. The authors report that as many

Table 1

Thematic Responses for Parents' Views on Gun Violence and a Positive Response to Teaching Gun Safety in Schools

\begin{tabular}{l} 
Prominent Themes \\
( $\mathrm{n}=$ \# of responses, \% of participants) \\
\hline Safely handling guns $(\mathbf{n}=\mathbf{2 4}, \mathbf{1 2 \%})$ \\
Education for tough subjects like gun safety is important because children, especially boys, play with guns. They use \\
sticks, bananas, or other toys as guns. If we do not teach them safety, then when they find a gun they will be more \\
likely to be unsafe. They should be taught about guns, and if they have questions, they should be addressed. If we \\
teach children how to handle guns, they will be less curious to know how to handle guns. We believe gun safety \\
education will help children know about guns and save their lives.
\end{tabular}

\section{Parents are not teaching gun safety to their children $(n=22,11 \%)$}

There have been too many accidents and deaths occurring with weapons, so, obviously, parents are not teaching the children at home; therefore, children need to be educated in order to prevent these horrible situations in our communities.

\section{Constitutional right $(\mathrm{n}=\mathbf{2 1}, \mathbf{1 0 . 5} \%)$}

The Second Amendment means guns are available. Gun ownership is a constitutional right. Training is better than banning gun ownership. Freedom to own arms is very important in our country.

\section{Education is knowledge and power $(n=19,9.5 \%)$}

Participants believed that education is knowledge and power, and that even if parents do not have guns, children may visit friends whose parents have guns and will need the knowledge in case they encounter problems with guns.

\section{Too many guns in the U.S homes $(n=18,9 \%)$}

Participants in this category believed that a lot of people in the U.S. have guns, and because of that many children are exposed to guns without appropriate supervision and instruction. Participants said further that guns are out there, and we cannot ignore them.

Gun safety should be part of the health curriculum $(\mathbf{n}=\mathbf{1 7}, \mathbf{8 . 5 \%})$
Participants in this category said children should be taught the proper way to use a firearm, and that firearm safety
should be a part of the health curriculum, following safety education like fire safety.
Schools should take the responsibility of teaching gun safety $(\mathbf{n}=\mathbf{1 4 , 7 \%})$
There exists the potential for gun violence in our schools, so schools should take the responsibility in case their
parents do not. School administrators need to know the seriousness of the topic because the worst tragedies with
guns have been in the schools.
Children are in danger around guns $(\mathbf{n}=\mathbf{1 3 , 6 . 5 \% )}$
Children should know the dangers involved with guns. They should be aware of the dangers of a loaded gun. They
should know that some guns are not like the ones they see in video games and that guns can kill. They should also
know that the guns in their video games are fake.
No reason $(\mathbf{n}=\mathbf{9}, \mathbf{4 . 5 \% )}$
Nine of the participants who said yes did not provide a reason.

as more than 225 deaths/injuries were recorded in one year, and they attribute this problem to the presence of loaded/unlocked gun storage in homes. Carbone and colleagues (2005) studied different gun-safety interaction techniques and their effectiveness. They found families receiving a specific clinical intervention were significantly better at meeting the safety guidelines for gun storage and removing guns from their homes $(61.6 \%)$ than those without specific instructions (26.9\%). Similarly, CoyneBeasley et al. (2001) found that widespread education on gun storage increases rates of safe firearm storage practices among parents.

On the other hand, unprotected storage of firearms can lead to unauthorized access to a gun by young people (Coyne-Beasley et al., 2001; Grossman, Reay, \& Baker, 1999; Brent, Perper, \& Allman, 1991), which could lead to 
suicide injuries. Despite the potential risk to children, Coyne-Beasley et al. (2001) found in their study that the presence of loaded and unlocked firearms is more prevalent in the homes of people with children than those without children (Coyne-Beasley et al., 2001). They indicated further that seventy-six percent $(76 \%)$ of the parents they studied who had guns believed that their kids were unfamiliar with where their guns were kept (Coyne-Beasley et al., 2001).

In summary, the available research suggests that health care professionals help with education and counseling programs to reduce the availability of loaded guns in homes (Becker et al., 1993; Carbone et al., 2005; Coyne-Beasley et al., 2001). It also recommends the distribution of gun locks to reduce the occurrence of improperly stored firearms in homes (Becker et al., 1993; Carbone et al., 2005; Coyne-Beasley et al., 2001). Concerning Indiana, where this research was conducted, it was noted by Nichols and O'Neill (2004) that the number of adults in Indiana who have gun permits was nearly 1 in 15 , and that people can get a gun permit once they become 18 years of age.

\section{The Present Study}

The above research provides significant insight into the problems that guns in the home, particularly unlocked guns, pose to children's lives. The missing link in this research has been parents' views on this issue, that is, whether or not they are in favor of gun safety education since, they are the key stakeholders that need to be on board on this issue. This paper examines parents' views on the possibility of the place for gun safety instruction in schools, and their views on gun violence, in order to explore possible ways to curb the ongoing gun-related injuries and deaths that occur among children. This paper hypothesizes that due to frequent instances of gun-related morbidity and mortality that occur unnecessarily among children, as reported by the media, the majority parents will be in favor of gun safety education.

\section{Methods}

\section{Study site and population}

This study took place in three counties in a Midwestern state in the United States, after approval from the Indiana University Institutional Review Board. Participants were recruited through a snowball sampling

Table 2

Thematic Responses for Parents' Views on Gun Violence and a Negative Response to Teaching Gun Safety in Schools

\section{Prominent Themes}

( $\mathrm{n}=$ \# of responses, $\%$ of participants)

Parents' responsibility $(n=15,7.5 \%)$

Participants in this group believe it is the parents' responsibility to teach their children about gun safety and that parents should determine whether their children are ready or not; this way parents can be sure of what is being taught to their children.

Children are too young for gun safety education $(n=14,7 \%)$

Children in elementary school years and younger are too young to be introduced to weapons; they could use reverse knowledge to cause harm.

No reason $(n=5,2.5 \%)$

Five of the participants who said "no" did not provide any reason.

Children will become more interested in using guns $(n=4,2 \%)$

Children have seen enough on TV about guns, and no more time should be spent on guns because children will become interested in them.

Schools should focus on teaching mathematics, science, and language arts rather than gun safety $(\mathrm{n}=2, \mathbf{1 \%})$

It should be the parents' decision after schools have mastered the art of teaching mathematics, English, science, and foreign languages.

Parents cannot trust the school system to teach gun safety $(n=2,1 \%)$

You cannot trust the school system to teach them (children) correctly about guns.

technique. Specifically, parents known to the researchers through personal contacts in the three counties where this research was implemented were contacted, and these parents also recruited other parent participants. The criterion for participation in this study was that participants had to be a parent of at least one Pre-K- $12^{\text {th }}$ grade student in one of the three counties where the research took place. Two 
hundred and fifty questionnaires were distributed to parents in person by the principal investigators and three research assistants, and 200 of them completed the questionnaires, giving a response rate of $80 \%$. The questionnaires were completed by the participants either in their individual homes or where it was convenient for them. Also, this survey administration was part of a larger study entitled "Dealing with unintentional injuries in Pre-K-6", which local parents and teachers participated in.

Table 3

\begin{tabular}{|c|c|}
\hline \multicolumn{2}{|c|}{$\begin{array}{c}\text { Number of Parents Who Prefer } \\
\text { that Gun Safety Be Taught in } \\
\text { Schools (n=128), by Grade at } \\
\text { which Gun Safety Should be } \\
\text { Taught. } \\
\end{array}$} \\
\hline \multicolumn{2}{|c|}{ Grade $\quad n(\%)$} \\
\hline \multicolumn{2}{|c|}{ Pre-K $\quad 3(1.5 \%)$} \\
\hline \multicolumn{2}{|r|}{$7(3.5 \%)$} \\
\hline $\mathrm{K} 1$ & $18(9.0 \%)$ \\
\hline & $10(5.0 \%)$ \\
\hline \multicolumn{2}{|r|}{$8(4.0 \%)$} \\
\hline \multicolumn{2}{|r|}{$24(12.0 \%)$} \\
\hline \multicolumn{2}{|r|}{$28(14.0 \%)$} \\
\hline \multicolumn{2}{|r|}{$30(15.0 \%)$} \\
\hline
\end{tabular}

\section{Instrumentation and procedures}

The anonymous questionnaire utilized for this study contained 11 open-ended and close-ended questions. Data for this research was collected by the principal investigators, three paid research assistants, and a volunteer parent in 2009.

Demographic questions. The demographic information in this study included participants' gender and where their children attended school. A little more than half of the participants did not complete race/ethnicity and age questions. We therefore did not take these variables into consideration for this study.
Open-ended questions. Three open-ended questions were developed by two experienced qualitative researchers, based on literature on firearms and children (Becker et al., 1993; Almond, 2008; Cummings et al., 1997; Carbone et al., 2005; Coyne-Beasley et al., 2001). The questions were pilot-tested with 36 respondents in 2007. The questions were pilot-tested to ensure that the content and the wording of the questions for the study were appropriate for the parents of school-aged children.

The open-ended questions included the following: Should gun safety be taught in schools? The possible answers were "Yes" and "No". The follow-up questions to the "Yes" answer were, "Why?", as well as, "When (at what grade level) do you think it should be taught?" (pre-kindergarten through sixth grade), and "Who should teach gun safety" (parents, teachers, policemen, or trained military personnel). The question "Why?" also followed the last two questions.

\section{Data coding and analysis}

Demographic information coding. The demographic data were separated by participants' gender and the schools that their children attended (e.g., public, private or home schooling). Percentages along with the frequencies in all cases were calculated. Chisquare tests were performed to determine whether participants' gender and their children's place of schooling were related to their endorsement of gun safety.

Thematic coding. The data coding began with open coding where coders closely examined various analytic concepts and categories. In the process of examining the data, similarities and differences in responses were identified. During the comparison process, new data categories were grouped with similar data and were given the same label or new labels as needed (Corbin $\&$ Strauss, 1998). The open-ended answers were sorted into categories and organized into themes for thematic analysis. The thematic analysis was based on parents' responses to the three 
questions on whether gun safety instructions should be taught in schools, at what level they should be taught, who should teach them, and their views on the questions.

The closed-ended questions involved generating frequencies or calculating percentages for parents' views on the three main questions stated above, along with the schools that the children attended. The results are presented in tables and thematic breakdowns to facilitate easy interpretation.

\section{Results}

\section{Demographics}

A majority of the population sample $(80 \%$, $\mathrm{n}=160)$ consisted of parents with children who attend public schools. Fifteen percent $(n=30)$ of the parents in the study had their children homeschooled, and $5 \% \quad(\mathrm{n}=10)$ of the children attended private schools. In general, the participants for this study were mostly mothers with a majority of their children attending public schools

At what level should gun safety instruction be taught in schools? Who should teach it?

There were $79 \% \quad(n=158)$ of parents who responded "yes" to the teaching of gun safety, whereas $21 \%(n=42)$ of parents responded "no" to gun safety instructions. The total sample included $55.5 \%(n=111)$ females and $39.5 \%(n=$ 79) males. Ten participants (5\%) did not indicate their sex.

A chi-square test revealed that a higher proportion of males $(96.2 \%)$ were in favor of gun safety compared to females $(64.8 \%$; $\mathrm{p}<$ $0.001)$. There were no significant differences between those parents whose children attended public and private schools on approval of gun safety education $(\mathrm{p}=0.78)$.

One hundred twenty-eight of the 158 parents who said "yes" answered the question relating to the grade level at which gun safety should be taught. Out of the 128, 64\%, $(n=82)$ indicated that teaching gun safety in the upper elementary grade levels (grade 4 and above) would be a good option; $36 \%$ of parents $(n=46)$ thought that teaching gun safety at lower grade levels (grade 3 and below) would be better. Out of the 158 parents who answered the question dealing with who should teach about gun safety, 71 of them $(45 \%)$ thought police/military personnel would be most suitable to teach gun safety. There were 25 parents (16\%) who thought they themselves should teach gun safety in schools. Only 3 parents (2\%) thought teachers should teach gun safety.

\section{Table 4}

\section{Thematic Responses for at What Grade Level Gun Safety Should be Taught in Schools}

\section{Prominent Themes}

( $\mathrm{n}=$ \# of responses, $\%$ of participants)

Grade four and above will be an ideal age for gun safety education $(n=82,41 \%)$

Participants in this group stated that fourth grade and above would be the right time to teach gun safety because children at that age are neither too young nor too old. They also stated that children at that age are learning and maturing; participants believe that children at this age would have a deep understanding of what they are learning. They stated further that unsupervised play begins at this age at homes, so it is important to teach children about guns before they are exposed to violence through video games, television, and friends.

The younger, the better $(n=46,23 \%)$

Members of this group said the sooner the children are taught about gun safety, the better. They stated that children should be taught the basics like 'If you see a gun, leave it alone' while they are developing and learning to understand the seriousness of guns. They noted that young children can be fascinated with guns, so the earlier they know the difference between toy guns and real guns, the better for their development.

The open-ended responses generated eight main themes for positive answers to teaching gun safety in schools. The eight positive themes are presented in Table 1.

\section{"No" to gun safety instruction in schools}

Five themes emerged from the negative 
responses to the teaching of gun safety in schools. Summaries of these themes are provided in Table 2.

\section{At what grade level should gun safety be taught?}

Table 3 provides a breakdown of the 128 parents who indicated their preference for the grade at which gun safety should be taught.

\section{Open-ended questions}

The open-ended data generated two themes as to when gun safety should be taught in schools. The themes included the following: 1) Grade four and above will be an ideal age for gun safety education, and 2) The younger, the better.

Summaries of these themes are provided in Table 4.

\section{Who should teach gun safety?}

Table 5 shows parents' preferences as to who should teach gun safety. Eight themes were derived from respondents' reasons for their selections as to who should teach gun safety.

\section{Discussion}

The focus of this research was to investigate parents' views on gun violence among children and whether gun safety should be taught in schools. From our data, and in line with our hypothesis, the majority of the parents surveyed were in favor of gun safety instruction in schools. The statistical data along with their written suggestions support this conclusion. Parents who took part in this research were also overwhelmed with the prevalence of gun-related morbidity and mortality in schools and at home, and indicated in their comments several times that if gun safety education were taught to children there would not be so many children exposed to gun-related dangers. The parents' concerns about the incidents of gun-related injuries and deaths among children are warranted. A report from the Children's Defense Fund (2006) indicates that deaths of preschoolers related to firearms were more than that of law enforcement officers killed in the line of duty in 2005.
Although a majority was in favor of teaching gun safety education, there were still several participants who were against it and brought up excellent points, including gun safety education being parents' responsibility, children of elementary school-age being too young for gun safety education, the danger of children becoming more interested in using guns, and the need for schools to focus on teaching mathematics, science, and language arts rather than gun safety. In effect, if gun safety education is to be implemented, stakeholders of schools would need to address major concerns that parents who are against the gun safety education have. One approach would be for teachers to collaborate with parents to appropriately address their concerns. For example, parents could have the choice to opt their child out of gun safety lessons.

A majority of the parents' data and comments suggest that teaching gun safety to young children would be detrimental to children's health, and that waiting for the children to mature before such instruction will ensure that they are ready for the lessons. In addition, a majority of parents were in favor of gun safety instructions being given by law enforcement officers because of their professional expertise.

\section{Limitations}

The findings of this study cannot be generalized to all parents in the United States, as this study was carried out in only one state. Also, the survey used personal contacts (snowball sampling) so it is likely that the sample was relatively homogeneous with regard to age, ethnicity, socioeconomic status, and other key variables that could be related to attitudes towards gun safety education. Additionally, we did not ask whether or not they were gun owners. A variable such as this one could strongly impact the results of this study.

In conclusion, this research has shown that gun safety instruction in schools might be appealing to parents. The recommendation of the parents who participated in the study was to include experts, such as law enforcement officers and 
parents. This approach may possibly lower morbidity and mortality associated with gun violence among children.

\section{Future studies and recommendations}

Future studies should explore what topics on gun safety parents believe should and should not be taught to children. Also, because parents indicated that they know their children better than other adults do, then curriculum specialists should collaborate with parents to develop appropriate curricula to help children acquire gun safety knowledge and skills. Furthermore, it is important for law enforcement officers to deliver the instruction, as a majority of parents in this study called for gun safety to be taught by law enforcement officers instead of either parents or teachers. The above recommendation may be one initiative that could help tackle the gun violence that is threatening the lives of children in schools and at home in the United States.

Table 5

Thematic Responses for Who Should Teach Gun Safety in Schools

Prominent Themes

( $\mathrm{n}=$ \# of responses, $\%$ of participants)

Law enforcement officials are trained and know more about guns $(n=71,45 \%)$

Respondents indicated that law enforcement officials have specific training and safety skills that make them more qualified than parents and teachers. They contend that law enforcement officials have more authority and more experience with handling, cleaning, and shooting guns. Since they are the most informed about gun safety, they will be of greater influence than someone not in uniform. They stated that law enforcement officials are the least likely to make mistakes, and that parents and teachers could teach the inaccurately and cause misunderstanding.

Parents, teachers, and police/military personnel are all adults that kids look up to in their communities $(\mathbf{n}=\mathbf{3 0}, \mathbf{1 9 \%})$

Parents who declared that gun safety should be taught by parents, teachers, and police/military personnel said all of these people are those whom kids look up to, and that looking up to multiple support systems within our culture would increase the children's understanding of gun safety. Also, parents said each and every member of the community has a communal responsibility to help raise children and to instruct them on the importance of gun safety in the society.

Gun safety instruction is the parents' role, not the teachers' or schools' $(n=25,16 \%)$

Respondents in this category noted that teaching about gun safety in schools might pique too many curiosities. They noted that teachers are teaching a lot of subjects, and that schools are for core subjects, not social issues. They said further that gun safety instruction is the parents' role, not teachers' or the schools'. Some noted that it was time for parents to educate and protect their children. Parents should have the right to choose how gun safety is taught, so that they will know exactly what is being taught and have control over what their children are taught.

Should be taught by trained and influential people $(n=16,10 \%)$

Respondents in this category noted that gun safety is a serious matter and should be taught by someone appropriately trained in that area, but that parents should also contribute because they are the most influential in their child's life.

\section{Others $(n=7,4 \%)$}

Everyone involved with children should be part of gun safety education.

Only by trained personnel $(n=3,2 \%)$

Respondents in this group wanted someone professional to teach children about gun safety, such as teachers, police, or military personnel.

Children will learn at home and in school $(\mathbf{n}=\mathbf{3}, \mathbf{2 \%})$

Respondents in this category noted that parents and teachers must provide gun safety lessons so that children will learn at home and in the school.

Teachers $(\mathbf{n}=\mathbf{3}, \mathbf{2 \%})$

It is the job of teachers to teach. 


\title{
References
}

Almond, L. (2008). School violence. Detroit: Greenhaven Press.

Becker, T.M., Olson, L., \& Vick, J. (1993). Children and firearms: A gunshot injury prevention program in New Mexico. American Journal of Public Health, 83(2), 282-283.

Brent, D.A, Perper, J.A., \& Allman, C. J. (1991). The presence and accessibility of firearms in the homes of adolescent suicides. Journal of the American Medical Association, 266, 2989-2995.

Carbone, P.S., Clemens, C.J., \& Ball, T.M. (2005). Effectiveness of gun-safety counseling and a gun lock giveaway in a Hispanic community. Archives of Pediatrics \& Adolescent Medicine, 159, 10491054.

Centers for Disease Control and Prevention. Youth Risk Behavior Survellience-United States, 2011. Morbidity and Mortality Weekly, 2012; 61:4 [6-7].

Children's Defense Fund. (2006). Retrieved from http://www.gunrpt-revise06-pdf. Accessed 2008.

Cook, P.J., \& Ludwig, J. (1996). Guns in America: Results of a comprehensive national survey on firearms ownership and use. Washington, DC: Police Foundation.

Corbin, J., \& Strauss, A. (1998). Basics of qualitative research: Techniques and procedures for developing grounded theory (2nd ed.). Thousand Oaks, CA: Sage.

Coyne-Beasley, T., Schoenbach, V.J., \& Johnson, R.M. (2001). "Love our kids, lock your guns": A community-based firearm safety counseling and gun lock distribution program. Archives of Pediatrics \& Adolescent Medicine, 155(6), 659-664.

Cummings, P., Grossman, D.C., Rivara, F.P., \& Koepsell, T.D. (1997). State gun safe storage laws and child mortality due to firearms. Journal of the American Medical Association, 278(13), 10841086.

Grossman, D., Reay, D., \& Baker, S. (1999). Self-inflicted and unintentional firearm injuries among children and adolescents: The source of the firearm. Archives of Pediatric Adolescent Medicine, 153, 875-878.

Johnson, R.M., Coyne-Beasley, T., \& Runyan, C.W. (2004). Firearm ownership and storage practices, U.S. households, 1992-2002: A systematic review. American Journal of Preventive Medicine, 27(2), 173-182.

Nichols, M., \& O'Neill, J. R. (2004) 300,000 Hoosiers have gun permits, 2012. Retrieved from http://www2.indystar.com/articles/1/161649-4651-009.html Accessed July 6, 2012

Schuster, M.A, Franke, T.M, Bastian, A., Sor, S., \& Halfon, N. (2000). Firearm storage patterns in US homes with children. American Journal of Public Health, 90(4), 588-594.

Substance Abuse and Mental Health Services Administration, Results from the 2010 National Survey on Drug Use and Health: Summary of National Findings, NSDUH Series H-41, HHS Publication No. (SMA) 11-4658. Rockville, MD: Substance Abuse and Mental Health Services Administration, 2011.

\author{
Author Information \\ *Cecilia S. Obeng, $\mathrm{PhD}$ \\ Indiana University \\ Department of Applied Health Science \\ Bloomington, IN 47405 \\ Email: cobeng@indiana.edu \\ Sean M. Bowman, MA \\ Indiana University \\ Department of Applied Health Science \\ * corresponding author
}

